\title{
Internacionalização e cooperação: Imperativos para os pequenos e médios negócios
}

\author{
Internationalization and cooperation: mandatory for small and medium business
}

\begin{abstract}
Resumo
A atuação no mercado externo é uma estratégia que vem sendo adotada pelas organizações como forma de alavancar ganhos competitivos. No entanto, as pequenas e médias empresas, em virtude de limitações de ordem técnica e gerencial, apresentam dificuldades para envolver-se em operações internacionais. Para mitigar esta situação, indica-se a cooperação interorganizacional. Neste sentido o presente artigo apresenta o objetivo geral de analisar como a cooperação viabiliza a internacionalização de pequenas e médias empresas do setor de bebidas do Estado de Sergipe. Para alcançar este objetivo foi realizado um estudo qualitativo, por meio do método de pesquisa Estudo de Caso, envolvendo três indústrias do setor de bebidas. Os resultados do estudo revelaram que por meio da cooperação as empresas pesquisadas aglutinaram diversos benefícios, tais como: redução de custos, acesso a novos mercados e obtenção de recursos produtivos e financeiros, os quais possibilitam atuar no mercado internacional.
\end{abstract}

Palavras chave: Cooperação, Internacionalização, Pequenas e médias empresas.

\begin{abstract}
The cooperative is seen as a major instrument for promoting economic and social development. For the cooperative to reach this stage, participation of the members is needed, mainly in the assemblies, which are the most representative organ of the organization. Thereby, this study hypothesized that the non-participation in meetings is due to lack of interest and lack of time from the cooperative medical branch. The methodologies used to verify this hypothesis were: document analysis, literature review and field research, by semi-structured interviews, which demonstrated a very low participation in the meetings of the last six years. We could conclude that the cooperative must have internal mechanisms of participation, mutual trust and voluntarism in actions, besides the adoption of an appropriate model of participation, low cost and highly representative.
\end{abstract}

Keywords: Cooperation, Internationalization, Small and medium enterprises.

Recebido: 22/12/2014 Aceito: 17/06/2015

Jefferson Reis Guimaraes Andrade ${ }^{1}$ e Maria Elena Leon Olave ${ }^{2}$

${ }^{1}$ Universidade Tiradentes, Mestre em Administração- jefferson.comex @ hotmail.com- Rua C, no 201 ,condomínio Bossa

Nova, Torre Brisa do Mar, Ap 805, Bairro Jabutiana, Aracaju/SE - CEP 49095 -833

${ }^{2}$ Universidade Federal de Sergipe, Doutora em Engenharia da Produção-mleonolave@gmail.com 


\section{Introdução}

A mundialização da concorrência, decorrente da abertura econômica e acordos comerciais entre vários países, indica que a entrada no mercado internacional não é uma escolha voluntária, mas sim imperiosa, para fazer frente ao aumento da competição e às constantes transformações produtivas e tecnológicas (SANTOS, 2015).

Desta forma, a internacionalização torna-se um processo fundamental para o fortalecimento das empresas e o aumento da competitividade dos países, em função dos seus impactos sobre os fluxos de comércio (acesso a novos mercados, ampliação da carteira de clientes, aumento da produção), tecnologias e divisas estrangeiras (CALDAS et. al., 2010; COVIELLO, 2006; SANTOS, 2015; ZAHRA; UCBASARAN; NEWEY, 2009).

O Brasil, como muitos países, tem sua economia concentrada nas pequenas e microempresas. Aproximadamente 99\% das empresas brasileiras são pequenos negócios (SEBRAE, 2011; 2013b). No entanto, verifica-se que participação das pequenas e médias empresas (PME's) brasileiras no mercado internacional é pouco expressiva. Dados oficiais revelam que estas organizações contribuem com aproximadamente $4,55 \%$ para o valor total das exportações do país (MDIC, 2014). Destaca-se ainda que no período de 2005 a 2013 o quantitativo de pequenas empresas exportadoras reduziu em 24,84\% (MDIC, 2014).

Os pequenos e médios exportadores apontam como principais problemas para a internacionalização: a própria estrutura da empresa (restrições financeiras, técnicas e operacionais); o ambiente competitivo do país e problemas relativos às condições de acesso aos mercados externos (SEBRAE, 2007; CARON; NASCIMENTO, 2012).

Todavia, observa-se que estes fatores podem ser neutralizados através de ações cooperativas entre organizações, partindo do pressuposto de que por meio da cooperação é possível desenvolver atividades em conjunto que possibilitam as PME's superar os problemas que impedem a sua internacionalização (CHETTY; ANGDAL, 2007; CHETTY; CAMPBELL-HUNT, 2004; FENSTERSEIFER, 2000; FREEMAN; EDWARDS; SCHRODER, 2006; JOHNSEN; JOHNSEN, 1999).

Diante do exposto, o presente artigo apresenta o objetivo geral de analisar como a cooperação viabiliza o processo de internacionalização das pequenas e médias empresas do setor de bebidas do Estado de Sergipe. E especificamente busca delinear o perfil das pequenas e médias empresas exportadoras; identificar os atores que cooperam para a internacionalização das empresas analisadas; verificar os tipos de cooperação desenvolvida pelas pequenas e médias empresas estudadas; e avaliar a contribuição da cooperação para o processo de internacionalização.

Justifica-se a realização deste estudo no setor de bebidas do Estado de Sergipe, tendo em vista que neste segmento empresarial existem pequenas e médias empresas indústrias atuando de forma consolidada no mercado internacional (MDIC, 2014). No entanto, a literatura não revela quais os laços cooperativos desenvolvidos por estas empresas.

A continuação apresenta o referencial teórico.

\section{Referencial teórico}

Este capítulo apresenta o referencial teórico do artigo, estruturado em três seções, contemplando a revisão da literatura nacional e internacional sobre a temática ora proposta.

\subsection{Cooperação interorganizacional}

Com o objetivo de se tornarem mais competitivas, as pequenas empresas vêm buscando soluções e caminhos alternativos por meio da cooperação (JUCHNIEVSKI; SOARES, 2013). Tal fato está associado ao reconhecimento de que as empresas, principalmente as de pequeno porte, não contemplam sozinhas todas as competências necessárias para manter a sua sobrevivência, o que tem levado estas firmas a buscarem em outras organizações os recursos que as complementem (FRANCO, 2007; REIS, 2008).

O propósito central da cooperação empresarial é reunir atributos que permitam uma adequação ao ambiente competitivo dentro de uma estrutura dinâmica sustentada por ações uniformizadas, mas descentralizadas, as quais possibilitem ganhos de escala com a união, sem perder a flexibilidade (BALESTRIN; VERSCHOORE, 2008).

Desta forma, pode-se definir a cooperação interorganizacional como o desenvolvimento de ativi- 
dades interligadas entre organizações, a fim de obter a integração sinérgica de recursos, competências e habilidades de vários parceiros (conhecimentos, informações, tecnologias, recursos financeiros $\mathrm{e}$ humanos), visando alcançar benefícios para os envolvidos na relação (CÂNDIDO, 2002; 2004; HALL, 1991; MAGGALHÃES; DAUDT; PHONLOR, 2009; MAZZATO; GOLO, 2011; SCHERMERHORN, 1975; VINHAS; BECKER, 2006; WINCKLER; MOLINARI, 2011).

Sendo assim a cooperação pode resultar na melhoria do produto, acesso à tecnologia, aperfeiçoamento do processo de gestão e na busca por alternativas que diminuam sua dependência do mercado interno no rumo à conquista de novos mercados, dentre outros benefícios (AMATO NETO, 200; JARILLO, 1988; JUCHNIEVSKI; SOARES, 2013; POWELL, 1998; SOUZA; BACIC, 1998; VERSCHOORE; BALESTRIN, 2006; 2008; WAARDEN, 1992).

No tocante a exploração de novos mercados, a próxima seção detalha como a cooperação contribui para a atuação no mercado internacional.

\subsection{Cooperação para internacionalização de pe- quenas e médias empresas}

Ser competitivo internacionalmente envolve a eficiência e a eficácia dos fatores produtivos, como: mão de obra; máquinas; equipamentos, fornecedores, tecnologias, novas técnicas, preços e modelos de gestão (CARON; NASCIMENTO, 2012).

Alcançar estas variáveis de forma isolada, por parte das pequenas empresas, torna-se difícil, em virtude de suas limitações técnicas, financeiras e operacionais (BOEHE; TONI, 2006; HOLLENSTEIN, 2005; OLIVEIRA; MARTINELLI, 2005).

Para superar estas limitações, as pequenas organizações podem desenvolver atividades de forma cooperativa, haja vista que por meio da cooperação é possível integrar competências e habilidades de várias firmas, culminando na obtenção dos recursos necessários para a internacionalização (CHETTY; ANGDAL, 2007; CHETTY; CAMPBELL-HUNT, 2004; FENSTERSEIFER, 2000; $\quad$ FREEMAN; EDWARDS; SCHRODER, 2006; JOHNSEN;
JOHNSEN, 1999).

Em outras palavras, as alianças entre as organizações constituem uma estratégia que proporciona unir forças e desenvolver atividades em conjunto, tais como: produção compartilhada, integração tecnológica, troca de conhecimentos, informações e experiências, as quais permitem às pequenas e médias empresas a penetração no mercado internacional e a obtenção de sucesso no processo de internacionalização (AMAL; FREITAG FILHO; MIRANDA, 2008; LEVY, MOTA; WERMELINGER, 2009; PRASHANTHAM, 2006).

Arruda e Arruda (1997) esclarecem que a formação destas conexões pressupõe a existência da intenção de alcançar benefícios por parte dos parceiros envolvidos na relação, ainda que a intenção de cada um possa ser diferente. Nesta configuração, pode-se admitir que, enquanto um parceiro pode objetivar a internacionalização, o outro pode pretender apenas fornecer tecnologia ou apoiar o processo de inserção internacional da empresa, em uma relação de benefícios mútuos.

Neste sentido Brito (1993), Fensterseifer e Vieira (2002) e Johanson e Vahlne (1990) afirmam que a cooperação para a internacionalização inclui interações com múltiplos atores, a exemplo de concorrentes, fornecedores, instituições financeiras, entidades estatais, clientes e consultores, dentre outros, que interagem para trocar informações, aprendizagem e recursos.

Estes atores podem estar localizados tanto no mercado local, quanto no mercado externo (FENSTERSEIFER; VIEIRA, 2002).

Em seguida, Costa e Ferreira (2000) destacam que a cooperação pode ser classificada de acordo com os seus objetivos, e não apenas de acordo a estrutura da interação entre organizações, como usualmente adotado. Neste sentido, ressalta-se que no campo da internacionalização, as principais tipologias de cooperação são Cooperação Tecnológica; Cooperação Comercial; Cooperação em marketing; Cooperação para Qualificação de Pessoal; Cooperação Financeira e Cooperação Fiduciária; Cooperação para a Produção e Cooperação na cadeia de logística internacional (EIRIZ，2001; POZZO; FINGER, 2010).

A continuação o Quadro 1 apresenta a descrição de cada das tipologias supracitadas. 


\section{Quadro 1 - Tipologia da cooperação por objetivo}

\begin{tabular}{|c|c|c|}
\hline TIPOLOGIA & OBJETIVO & DESCRIÇÃO \\
\hline $\begin{array}{l}\text { Cooperação } \\
\text { Tecnológica }\end{array}$ & $\begin{array}{l}\text { Eliminar insuficiências tec- } \\
\text { nológicas por meio da cola- } \\
\text { boração com empresas tec- } \\
\text { nologicamente mais dotadas }\end{array}$ & $\begin{array}{l}\text { As principais alianças de domínio tecnológico são: (1) } \\
\text { Formação e/ou assistência técnica compartilhada, (2) } \\
\text { Acordo para investigação e desenvolvimento conjunto de } \\
\text { novos produtos e processos, rateando os custos ligados a } \\
\text { esta atividade. }\end{array}$ \\
\hline $\begin{array}{c}\text { Cooperação } \\
\text { Comercial }\end{array}$ & $\begin{array}{l}\text { Ampliar os espaços merca- } \\
\text { dológicos com plena utiliza- } \\
\text { ção da capacidade operacio- } \\
\text { nal. }\end{array}$ & $\begin{array}{l}\text { Os principais acordos nesta área são: (1) Grupo de expor- } \\
\text { tadores, (2) Acordo de distribuição, estabelecido geralmen- } \\
\text { te entre uma empresa produtora de bens finais e outra } \\
\text { empresa que possui domínio ou presença nas redes de } \\
\text { distribuição do produto ao consumidor final; (3) Acordo de } \\
\text { representação, firmado quando uma empresa se torna a } \\
\text { representante dos produtos e marcas da outra empresa para } \\
\text { determinado mercado; e (4) Central de compras, estabele- } \\
\text { cida entre as empresas do mesmo setor e/ou que possuem } \\
\text { as mesmas necessidades de matérias primas, que se inte- } \\
\text { gram para obter economias de escala e adquirir maior } \\
\text { poder de barganha junto aos fornecedores. }\end{array}$ \\
\hline $\begin{array}{l}\text { Cooperação em } \\
\text { Marketing }\end{array}$ & $\begin{array}{l}\text { Melhorar e reforçar de ima- } \\
\text { gem da empresa; trocar } \\
\text { informações mercadológi- } \\
\text { cas, penetrar em novos mer- } \\
\text { cados. }\end{array}$ & $\begin{array}{l}\text { Envolve relacionamento com clientes, fornecedores e } \\
\text { distribuidores, dentre outros agentes econômicos e sociais, } \\
\text { que interagem para a promoção de um produto em deter- } \\
\text { minada praça ou disponibilizam dados sobre a configura- } \\
\text { ção que um produto para determinado mercado. }\end{array}$ \\
\hline $\begin{array}{l}\text { Cooperação de } \\
\text { Qualificação de } \\
\text { Pessoal }\end{array}$ & $\begin{array}{l}\text { Capacitação, reciclagem e } \\
\text { formação do pessoal. }\end{array}$ & $\begin{array}{l}\text { Parcerias com instituições de ensino público ou privado, } \\
\text { ou agências de fomento. }\end{array}$ \\
\hline $\begin{array}{l}\text { Cooperação } \\
\text { Financeira }\end{array}$ & Manutenção de crédito & $\begin{array}{l}\text { Envolve essencialmente os bancos, para manutenção de } \\
\text { crédito em condições adequadas e financiamento do de- } \\
\text { senvolvimento de pesquisas e produtos. }\end{array}$ \\
\hline $\begin{array}{l}\text { Cooperação } \\
\text { Fiduciária }\end{array}$ & $\begin{array}{l}\text { Financiar/comprar equipa- } \\
\text { mentos }\end{array}$ & $\begin{array}{l}\text { Ocorre através de consórcios ou associações que oferecem } \\
\text { garantias às empresas afiliadas, para financiamentos ou } \\
\text { compra de equipamentos. }\end{array}$ \\
\hline $\begin{array}{l}\text { Cooperação na } \\
\text { Produção }\end{array}$ & $\begin{array}{l}\text { Viabilizar, aperfeiçoar ou } \\
\text { reduzir custos do processo } \\
\text { de produção }\end{array}$ & $\begin{array}{l}\text { Os principais acordos nesta área são: (1) subcontratação, } \\
\text { representada pela aliança em que uma empresa (contratan- } \\
\text { te) subcontrata a outra (subcontratada) uma parte do seu } \\
\text { processo de produção; (2) Acordo de produção conjunta, } \\
\text { firmado por duas ou mais empresas que produzem conjun- } \\
\text { tamente os mesmos produtos, pois sozinhas não conse- } \\
\text { guem atender a demanda do mercado; (3) Licenciamento } \\
\text { de Patentes, estabelecida quando uma empresa (concessio- } \\
\text { nária) concede a outra (licenciada) os direitos de explora- } \\
\text { ção de uma patente, produto ou processo de fabricação, } \\
\text { mediante uma compensação, geralmente de carácter finan- } \\
\text { ceiro, denominada de royalties. }\end{array}$ \\
\hline $\begin{array}{l}\text { Cooperação na } \\
\text { Cadeia de Su- } \\
\text { primentos da } \\
\text { Logística In- } \\
\text { ternacional }\end{array}$ & $\begin{array}{l}\text { Compartilhamento de opera- } \\
\text { ções e fretes e terceirização } \\
\text { logística para viabilizar o } \\
\text { envio de mercadorias ao } \\
\text { exterior. }\end{array}$ & $\begin{array}{l}\text { Os tipos mais comuns de aliança na cadeia de suprimentos } \\
\text { são (1) logística terceirizada; (2) compartilhamento de } \\
\text { frete (3) integração do distribuidor. }\end{array}$ \\
\hline
\end{tabular}

Fonte: Elaborado pelos autores (2013), com base em Costa e Ferreira (2000), Eiriz (2001) e Pozzo e Finger (2010). 
Em seguida apresenta-se o modelo analítico da pesquisa.

\subsection{Modelo análitico}

Conforme explicitado inicialmente, as pequenas e médias empresas possuem limitações de ordem estratégica e operacional que as impedem de atuar mercado internacional (BOEHE; TONI, 2006;
HOLLENSTEIN, 2005, OLIVEIRA; MARTINELLI, 2005). Todavia, estas limitações podem ser superadas por meio da cooperação interorganizacional.

Neste sentido, foi elaborado o modelo analítico descrito na figura 1 , levando em consideração os pressupostos teóricos acima apresentados, a fim de nortear o desenvolvimento desta pesquisa.

Figura 1 - Modelo Analítico: Cooperação para a Internacionalização

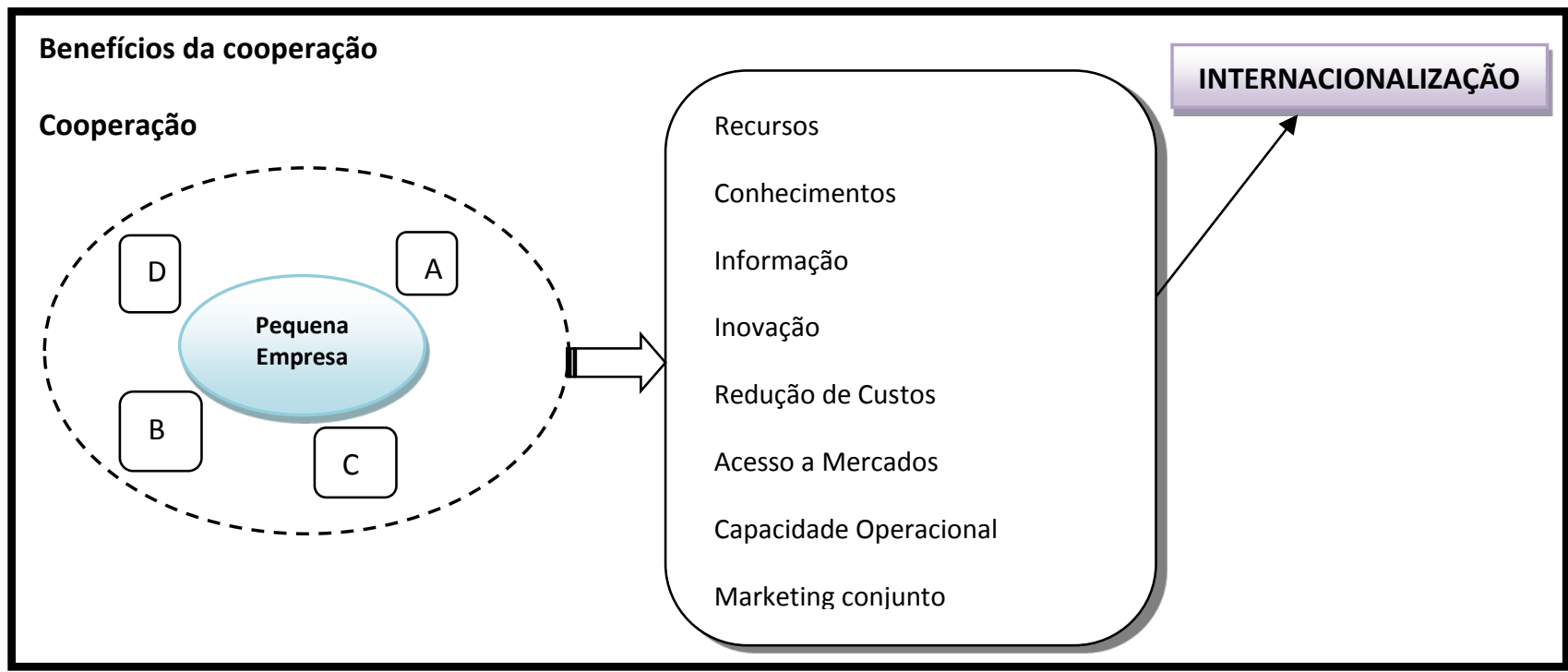

Fonte: Elaborado pelo autor (2013)

O esquema analítico apresenta como unidade de análise a pequena ou média empresa. E em seguida, busca identificar os atores (A, B, C, D) que cooperam para a internacionalização da unidade de análise, os quais podem estar localizados tanto no mercado doméstico quanto internacional (BRITO, 1993; FENSTERSEIFER; VIEIRA, 2002; GALLON; ENSLIN; SILVEIRA, 2009; JOHANSON E VAHLNE, 1990)

$O$ modelo indica que por meio da cooperação interorganizacional a unidade de análise (pequena ou média empresa) passa a obter diversos recursos e benefícios estratégicos, a saber: redução de custos, capacidade de desenvolver e lançar novos produtos em menor tempo; produção em escala; qualidade; adequação tecnológica, inovação e estratégias de marketing conjunto (AMAL; FREITAG FILHO; MIRANDA, 2008; LEVY; MOTA; WERMELINGER, 2009; PRASHANTHAM, 2006).

Por fim, o modelo em questão demonstra que o conjunto de vantagens acima apresentado possibilitará neutralizar os fatores que impedem as pequenas empresas de atuar no mercado externo (CHETTY; ANGDAL, 2007; CHETTY; CAMPBELL-HUNT, 2004; FENSTERSEIFER, 2000; FREEMAN; EDWARDS; SCHRODER, 2006; JOHNSEN; JOHNSEN, 1999).

Em seguida, apresentam-se os procedimentos metodológicos.

\section{Procedimentos metodológicos}

Para atingir os objetivos traçados neste artigo, foi realizada uma pesquisa de natureza qualitativa, pautando-se na análise aprofundada do objeto de estudo, de modo a permitir a compreensão detalhada do fenômeno avaliado (GODOY, 1995; RICHARDSON, 1999).

$\mathrm{O}$ artigo pode ser classificado como exploratório, ao passo que buscou identificar os atores e tipos de cooperação desenvolvida pelas empresas avaliadas, os quais ainda não tinham sido elencados pela lite- 
ratura, abrindo espaço para estudos futuro. E descritivo, ao buscar delinear como a cooperação contribui para a internacionalização das pequenas empresas do setor de bebidas do Estado de Sergipe (NEUMAN, 1997; SAUNDERS; LEWIS; THORNILL, 2000).

Como método de pesquisa, adotou o Estudo de Caso. Esta técnica se mostrou como mais adequada ao escopo do trabalho, uma vez que Yin (2005) e Martins (2008) entendem que o mesmo trata-se de uma estratégia que aborda o problema de forma dinâmica, aprofundada, dentro de seu contexto real, conforme proposto neste artigo.

A fim de atender os objetivos do estudo, os casos que fazem parte da pesquisa foram escolhidos com base nos seguintes critérios: a) empresa de pequeno ou médio porte; b) empresa internacionalizada; b) empresa do setor de bebidas do Estado de Sergipe.
Levando em consideração os critérios acima, foram identificadas três empresas que se enquadraram nos requisitos antes elencados. Registra-se que as empresas aceitaram participar desta pesquisa e tiveram as suas identidades preservadas.

As empresas que compõem o estudo, identificadas pelas letras "A", "B" e "C", são indústrias localizadas na região centro-sul do Estado de Sergipe, cujo perfil encontra-se descrito no próximo capitulo.

Desta forma, o artigo pode ser classificado como estudo de casos múltiplos, pois contemplou a analise de várias firmas, possibilitando maior riqueza de informações e resultados (YIN, 2005).

Para guiar a coleta de dados, bem como a análise e discussão dos resultados foram elaboradas as questões de pesquisa, categorias analíticas e elementos de análise, descritas no quadro 2 abaixo.

Quadro 2 - Questões de Pesquisa, Categorias analíticas e Elementos de Análise

\begin{tabular}{|l|c|l|}
\hline \multicolumn{1}{|c|}{ QUESTÕES DE PESQUISA } & $\begin{array}{c}\text { CATEGORIAS ANA- } \\
\text { LÍTICAS }\end{array}$ & \multicolumn{1}{|c|}{ ELEMENTOS DE ANÁLISE } \\
\hline $\begin{array}{l}\text { Qual o perfil das pequenas e médias empre- } \\
\text { sas do setor de bebidas do estado de Sergi- } \\
\text { pe? }\end{array}$ & Perfil da empresa & $\begin{array}{l}\text { Localização } \\
\text { Fundação } \\
\text { Produtos fabricados } \\
\text { Produtos exportados }\end{array}$ \\
\hline $\begin{array}{l}\text { Quais os atores que cooperam para a inter- } \\
\text { nacionalização da empresa? }\end{array}$ & Atores da cooperação & $\begin{array}{l}\text { Fornecedores } \\
\text { Concorrentes } \\
\text { Clientes } \\
\text { Bancos } \\
\text { Órgãos de pesquisa } \\
\text { Orgãos governamentais }\end{array}$ \\
\hline $\begin{array}{l}\text { Quais os tipos de cooperação desenvolvida } \\
\text { pelas pequenas e médias empresas do Setor } \\
\text { de Bebidas do Estado de Sergipe? }\end{array}$ & $\begin{array}{l}\text { Tipos de cooperação } \\
\text { Cooperação Tecnológica } \\
\text { Cooperação Comercial } \\
\text { Cooperação em Marketing } \\
\text { Cooperação de Qualificação de } \\
\text { Pessoal } \\
\text { Cooperação Financeira } \\
\text { Cooperação Fiduciária } \\
\text { Cooperação na Produção } \\
\text { Cooperação na Cadeia de Supri- } \\
\text { mentos da Logística Internacional }\end{array}$ \\
\hline $\begin{array}{l}\text { Quais as contribuições da cooperação para o } \\
\text { processo de internacionalização? }\end{array}$ & $\begin{array}{l}\text { Contribuições da coo- } \\
\text { peração para a inter- } \\
\text { nacionalização }\end{array}$ & $\begin{array}{l}\text { Recursos } \\
\text { Redução de custos } \\
\text { Informação } \\
\text { Conhecimento }\end{array}$ \\
\hline
\end{tabular}

Fonte: Elaborado pelos autores (2013)

Nesta pesquisa foi adotada como instrumento de coleta de dados a (1) a entrevista, na modalidade semi-estruturada, utilizando-se de um roteiro de perguntas predefinidas, porém flexíveis, e (2) a aná- lise de documentos, com base nas orientações de Saunders, Lewis e Thornill (2000).

$\mathrm{O}$ roteiro de perguntas da entrevista foi estruturado em três blocos. $\mathrm{O}$ primeiro delineou o perfil da 
empresa, questionando dados técnicos sobre a organização, tais como: fundação, produtos fabricados, destino das exportações e etc. $\mathrm{O}$ segundo bloco analisou os atores que cooperam com as organizações pesquisadas. A terceira parte investigou as contribuições da cooperação para a internacionalização da firma, permitindo identificar os tipos de relacionamentos cooperativos.

A entrevista foi aplicada ao representante de cada uma das empresas estudadas, totalizado três entrevistas, com duração de aproximadamente 40 (quarenta) minutos cada uma, no $1^{\circ}$ semestre do ano de 2013.

Todas as entrevistas foram gravadas e o áudio foi analisado diversas vezes durante a transcrição dos casos, visando identificar todas as informações disponibilizadas pelos entrevistados.

Os dados coletados na pesquisa de campo foram analisados qualitativamente por meio da Análise de Conteúdo. Está técnica, segundo Bardin (2008), corresponde à análise das comunicações, neste caso, os textos transcritos das entrevistas, com o propósito de inferir a partir de trechos, orações ou frases extraídas das comunicações (respostas emitidas pelos entrevistados) as informações necessárias para atender aos objetivos do estudo.

Os documentos analisados no estudo contemplaram: portfólios (catálogos) das empresas avaliadas e documentos oficiais (Relatórios da Balança Comercial Nacional e Local, Tabelas de Exportadores, Gráficos de Participação no Mercado Externo), disponibilizados pelo Ministério do Desenvolvimento, Indústria e Comércio Exterior - MDIC.

Os documentos acima citados foram utilizados para validar algumas informações dispostas nas entrevistas.

Os casos que compõem esta pesquisa foram transcritos individualmente. Após, realizou-se a análise conjunta dos três casos a luz do referencial teórico deste artigo e do modelo analítico descrito na figura 1 , conforme exposto no capítulo quatro abaixo.

A transcrição individual dos casos foi suprimida do artigo em virtude da indisponibilidade de laudas, constando a seguir a análise comparativa dos casos.

\section{Análise comparativa dos casos e discussão dos resultados}

Este capítulo apresenta a análise comparativa dos três casos tratados neste estudo. Cabe salientar que cada caso corresponde a uma determinada empresa, cuja identificação foi resguarda, em face de solicitação dos empresários.

Destaca-se, com base no MDIC (2013) que as empresas alcançadas nesta pesquisa correspondem à totalidade de firmas exportadoras do setor de bebidas do Estado de Sergipe. Em seguida, registra-se que estas organizações exportam aproximadamente $60 \%$ do valor total comercializado no exterior pelo Estado.

Desta forma, contrariando o panorama nacional (no qual as PMES contribuem com apenas 4,5\% para o valor total exportado/ano), o Estado de Sergipe, possui a maior parte das suas exportações sendo executada por pequenas e médias empresas, cujo perfil encontra-se delineado a seguir.

\subsection{Perfil das pequenas e médias empresas in- ternacionalizadas do setor de bebidas do Estado de Sergipe}

As empresas que compõem a pesquisa de campo deste artigo, identificadas pelas letras "A", "B" e "C", são indústrias localizadas na região centro-sul do Estado de Sergipe, especificamente nos municípios de Estância/SE e Boquim/SE, conforme detalhado no quadro 03 abaixo.

Estas indústrias foram criadas nos anos de 1998, 2006 e 2001, empregam 310, 94 e 240 pessoas, respectivamente, sendo enquadradas como empresas de pequeno e médio porte, conforme classificação adotada pelo SEBRAE ( ${ }^{\circ}$ de empregados).

As empresas " $A$ " e " $C$ " produzem sucos concentrados e integrais de frutas cítricas e tropicais, destinados em maior escala ao mercado externo e secundariamente ao mercado interno. Já a empresa "B" além de produzir o suco concentrado para o exterior, também possui uma linha de sucos prontos destinados ao consumidor final do mercado doméstico.

Desta forma, foi possível evidenciar que as três indústrias estudadas exportam apenas os sucos concentrados ou integrais, com destaque para o suco concentrado de laranja, o qual apresentou uma elevada escala de comercialização por todas as indústrias estudadas.

Estes dados foram ratificados por meio da analise da Balança Comercial do Estado de Sergipe, a qual revela que os sucos representam o principal 
produto da pauta de exportações do estado, representando mais de $50 \%$ do total das exportações locais (MDIC, 2013), Destaca-se ainda que não exis- tem outros produtos do setor de bebidas, além dos sucos concentrados e integrais, sendo exportado pelo Estado de Sergipe, vide tabela 1.

Tabela 1 - Principais itens da pauta de exportações do Estado de Sergipe no ano de 2013

\begin{tabular}{|l|l|l|}
\hline PRINCIPAIS PRODUTOS EXPORTADOS & US\$ (F.O. B) & PARTICIPAÇÃO (\%) \\
\hline Sucos de laranja, congelados, não fermentados. & 47.903 .408 & 50,40 \\
\hline Outros sucos de laranja, não fermentados. & 10.316 .551 & 10,85 \\
\hline
\end{tabular}

Fonte: MDIC (2013)

Os sucos exportados por serem concentrados ou integrais não se destinam ao consumidor final e são comercializados no mercado externo para outras empresas, localizadas em diversos países (vide quadro 3), que os transformam, principalmente, em sucos instantâneos e refrigerantes.

As três indústrias utilizam como estratégia de internacionalização a exportação direta. As empresas "A" e "C" exportam deste o início das suas atividades, pois foram criadas com o perfil de atender ao mercado externo, motivadas pelo elevado potencial de consumo de sucos nos países europeus, quando comparado ao Brasil e pelo preço que o mercado internacional paga por estes produtos. A empresa "B", por sua vez, iniciou as exportações 05 anos após a sua abertura, em virtude de pedidos oriundos do exterior e como forma de vender o excedente da produção não absorvida pelo mercado interno.

O quadro 03 abaixo apresenta a síntese do perfil das empresas que compõem este estudo.

Quadro 03 - Perfil das empresas internacionalizadas do setor de bebidas

\begin{tabular}{|c|c|c|c|}
\hline Perfil da empresa & Empresa "A" & Empresa "B" & Empresa "C" \\
\hline Localização & Estância/SE. & Boquim/SE. & Estância/SE. \\
\hline Fundação & 1998 & 2006 & 2001 \\
\hline Início das Exportações & Exporta desde a fundação. & Exporta desde 2011. & Exporta desde a fundação. \\
\hline $\begin{array}{l}\text { Quantidade de Empre- } \\
\text { gados }\end{array}$ & 310 & 94 & 240 \\
\hline Porte Empresarial & Médio Porte & Pequeno Porte & Médio Porte \\
\hline Produtos fabricados & $\begin{array}{l}\text {-Sucos concentrados e integrais } \\
\text { de frutas cítricas e tropicais; } \\
\text { - Produtos derivados da laranja } \\
\text { (D’limonene, Oleo Essencial de } \\
\text { Lima Ácida, Célula de Laranja } \\
\text { Pasteurizada, Óleo Essencial de } \\
\text { Laranja); } \\
\text {-Essência de Abacaxi. }\end{array}$ & $\begin{array}{l}\text {-Sucos prontos de diversas } \\
\text { frutas como manga, abaca- } \\
\text { xi, goiaba, uva, laranja e } \\
\text { outras, destinados ao con- } \\
\text { sumo final; } \\
\text {-Sucos concentrados e } \\
\text { integrais de laranja. }\end{array}$ & $\begin{array}{l}\text {-Sucos concentrados de laran- } \\
\text { ja, maracujá, manga, abacaxi } \\
\text { e outras frutas; } \\
\text {-Sucos integrais de graviola, } \\
\text { goiaba e acerola; } \\
\text {-Subprodutos da laranja: } \\
\text { d'limonene, óleo essencial, } \\
\text { essência e o pulpwash. }\end{array}$ \\
\hline Produtos exportados & $\begin{array}{l}\text {-Sucos concentrados e integrais } \\
\text { de frutas cítricas e tropicais. } \\
\text { - Produtos derivados da laranja. }\end{array}$ & $\begin{array}{l}\text {-Sucos concentrados } \mathrm{e} \\
\text { integrais de laranja. }\end{array}$ & $\begin{array}{l}\text {-Sucos concentrados de laran- } \\
\text { ja, maracujá e abacaxi. }\end{array}$ \\
\hline $\begin{array}{c}\text { Estratégia de Internaci- } \\
\text { onalização }\end{array}$ & - Exportação direta. & - Exportação direta. & - Exportação direta. \\
\hline $\begin{array}{l}\text { Principais destinos das } \\
\text { exportações }\end{array}$ & $\begin{array}{l}32 \text { (trinta e dois) países, sendo: } \\
18 \text { na Europa; } \\
06 \text { na Ásia; } \\
02 \text { da América do Norte } \\
\text { (Estados Unidos e Canadá); } \\
04 \text { da América Central; } \\
02 \text { na América do Sul (Argentina } \\
\text { e Chile). }\end{array}$ & $\begin{array}{l}\text { - Estados Unidos; } \\
\text { - Canadá. }\end{array}$ & $\begin{array}{l}\text { - Alemanha; } \\
\text { - Bélgica; } \\
\text { - Croácia; } \\
\text { - E spanha; } \\
\text { - Ucrânia; } \\
\text { - Holanda; } \\
\text { - Reino Unido; } \\
\text { - Arábia Saudita; } \\
\text { - Emirados Árabes; } \\
\text { - Israel. }\end{array}$ \\
\hline
\end{tabular}

Fonte: Dados da pesquisa (2013) 
Salienta-se que as três firmas possuem atuação consolidada no mercado internacional.

A seguir estão identificados os atores que cooperam para a internacionalização das empresas acima descritas, e os benefícios oriundos destes relacionamentos para a internacionalização.

\subsection{Cooperação interorganizacional para a inter- nacionalização das empresas do setor de bebidas do Estado de Sergipe}

Esta seção trata dos relacionamentos cooperativos das organizações pesquisadas e dos benefícios oriundos destas relações para o (1) ingresso e (2) atuação do mercado internacional.

\section{a)Ingresso no mercado internacional}

No tocante a cooperação para o ingresso no mercado internacional à pesquisa revelou que a empresa "B" foi induzida a acessar o mercado externo a partir da cooperação com um agente comercial no exterior, o qual incentivou a indústria a comercializar no exterior.

Segundo o empresário desta firma, a agência no exterior os localizou no Brasil e apresentou uma proposta de parceria comercial para exportação. $\mathrm{Na}$ relação firmada, a empresa parceira investiu com a indicação dos importadores, tendo como retorno uma comissão por lote exportado.

O mesmo empresário afirmou que sem esta parceria provavelmente a empresa " $\mathrm{B}$ " não estaria atuando no mercado externo, pois além de não estar atenta a este mercado, também não teria condições de sozinha acionar a carteira de clientes que hoje atende no exterior.

Não foram registrados laços de cooperação para o ingresso das empresas " $\mathrm{A}$ " $\mathrm{e}$ " $\mathrm{C}$ " no mercado internacional, pois estas firmas foram criadas em 1998 e 2001 com a finalidade de atender ao mercado externo, pois já visualizaram o potencial exportador dos sucos, especialmente para o mercado europeu.

\section{b)Atuação no mercado internacional}

Para atuar no mercado internacional, a pesquisa mostrou que as empresas "A", "B" e " $C$ " cooperam tanto com atores nacionais, quanto internacionais.
Neste quesito as três indústrias afirmaram que mantém cooperação com (1) empresa de logística, (2) despachante aduaneiro e (3) fornecedores, alegando que sem estas parceriais não conseguiriam comercializar no exterior, pois não teriam condições de:

- Embarcar as mercadorias para o exterior, uma vez que o volume de carga não contempla uma embarcação (navio), carecendo cooperar com empresas de logística para consolidar a sua carga a de outras firmas e com isso, ratear o frete do navio, viabilizando o embarque da mercadoria;

- Despachar de forma independente as suas mercadorias no porto (despacho própia), ensejando a necessidade de cooperar com despachantes aduaneiros, a fim de reduzir custos e viabilizar os processos de despacho;

- Conseguir os insumos necessários para a produção, especialmente no padrão internacional, induzindo a cooperar com os seus forncedores.

Nesta mesma linha, as empresas " $A$ " e "C" destacam outros atores com quem cooperam para atuar no mercado externo. As firmas em destaque relataram que seria imopssivel atender sozinhas a determinados clientes que possuem necessidades especiais de pronta entrega. Sendo assim, passaram a cooperar com câmaras frigorifas no exterior (porto de Rotterdam), a fim de armanezar o seu produto no país de destino, garantindo pronta entrega ao cliente que não pode aguardar o envio da mercadoria para o exterior (média 7 a 15 dias).

A empresa "A", em seguida, destacou a sua coperação com os bancos, por meio de financiamentos "especiais" para modernizar o seu parque industrial, a fim de atender aos padrões internacinais. Além deste parceiro, a empresa " $\mathrm{A}$ " também salientou a cooperação com os seus clientes, afirmando que os mesmos disponibilizam informações sobre tendências mercadológicas; dados sobre novos consumidores; perfil de produtos que estão sendo mais procurados; melhorias que um produto deve ter em sua configuração.

Desta forma, pode-se afirmar que as três empresas estudadas nesta pesquisa apresentaram a sua rede de cooperação formada por múltiplos atores, resultando em uma estrutura de dependência e adaptação voltada para ingressar e atuar no mercado externo (BRITO, 1993; FENSTERSEIFER; VIEIRA, 2002; JOHANSON; VAHLNE, 1990).

Este panorama confirma os pressupostos teóricos defendidos pelos autores Chetty e Angdal (2007), 
Chetty e Campbell-Hunt (2004), Fensterseifer (2000), Freeman, Edwards e Schroder (2006) e Johnsen e Johnsen (1999) de que por meio da cooperação é possível neutralizar os fatores que impedem a atuação das empresas no mercado internacional.

O quadro 4 apresenta a síntese detalhada das contribuições de cada um dos atores acima mencionados para a atuação das empresas " $\mathrm{A}$ ", "B" e "C" no mercado externo.

\section{Quadro 4 - Contribuições da cooperação para a internacionalização}

\begin{tabular}{|c|c|}
\hline ATOR & DESCRIÇÃO DA CONTRIBUIÇÃO \\
\hline Fornecedores & $\begin{array}{l}\text { Parceiro comum das três empresas. } \\
\text { As empresas "A" e "B" cooperam com os produtores de laranja fornecendo apoio ao plantio } \\
\text { por meio de informações relacionadas ao controle de pragas, ponto de maturação e utilização } \\
\text { de fertilizantes, a fim de obter frutas para o processamento de acordo com os padrões interna- } \\
\text { cionais. No caso da empresa "C", a mesma disponibiliza o frete do insumo até o pátio da in- } \\
\text { dústria, além de um profissional para avaliar se as frutas podem ser colhidas, ou seja, se aten- } \\
\text { dem aos padrões de qualidade exigidos pela empresa. }\end{array}$ \\
\hline $\begin{array}{c}\text { Despachante } \\
\text { aduaneiro }\end{array}$ & $\begin{array}{l}\text { As empresas "A", "B" e "C" afirmaram que seria inviável credenciar um profissional do seu } \\
\text { quadro e estabelecer escritório na área portuária para executar diretamente a atividade de des- } \\
\text { pacho da carga, pois isto acarretaria em altos custos, reduzindo o potencial competitivo das } \\
\text { mesmas. Para sanar esta limitação, as empresas adotaram parcerias com profissionais especia- } \\
\text { lizados nesta atividade, denominados de despachantes aduaneiros, que atuam de forma "tercei- } \\
\text { rizada" no desembaraço da carga para exportação. }\end{array}$ \\
\hline $\begin{array}{l}\text { Empresa de } \\
\text { Logística } \\
\text { Internacional }\end{array}$ & $\begin{array}{l}\text { As três indústrias indicaram que sozinhas não conseguem fechar o frete para exportação, ou } \\
\text { seja, não possuem carga suficiente para completar uma embarcação e mediante parceria com } \\
\text { empresas de logística internacional é possível consolidar a sua carga e de outras empresas e } \\
\text { com isso obter o frete rateado, viabilizando a embarcação dos seus produtos. }\end{array}$ \\
\hline Bancos & $\begin{array}{l}\text { A empresa " } A \text { " buscou este parceiro com o objetivo de acessar a recursos financeiros para } \\
\text { investir na modernização do parque industrial e melhoria da produção, a fim de atender aos } \\
\text { requisitos do mercado externo. }\end{array}$ \\
\hline Clientes & $\begin{array}{l}\text { A empresa "A" entende que os seus clientes são parceiros no negócio. Na visão do empresário } \\
\text { entrevistado, o contato freqüente com os clientes, tanto por telefone e e-mail, quanto em visi- } \\
\text { tas, possibilita trocar conhecimentos, experiências e obter informações a respeito do mercado, } \\
\text { tais como tendências mercadológicas; informações sobre novos consumidores; perfil de produ- } \\
\text { tos que estão sendo mais procurados; quais as melhorias que um produto deve ter em sua con- } \\
\text { figuração e quais os novos produtos que devem ser inseridos na linha de produção. }\end{array}$ \\
\hline $\begin{array}{l}\text { Locadores de } \\
\text { Câmaras } \\
\text { Frigoríficas } \\
\text { no exterior }\end{array}$ & $\begin{array}{l}\text { As empresas "A" e "C" firmaram parcerias com frigoríficos no exterior, com a finalidade de } \\
\text { armazenar suco, visando atender a alguns importadores que não se dispõem a aguardar o tem- } \\
\text { po de transporte da carga até o país de destino. } \\
\text { Estas câmaras ficam localizadas estrategicamente no porto de Rotterdam na Holanda e por } \\
\text { meio delas é possível comercializar o produto com um prazo de entrega de no máximo } 24 \\
\text { horas após a solicitação do cliente. Os empresários ressaltaram que sem esta parceria muitos } \\
\text { contratos, principalmente com as grandes empresas, não seriam firmados. }\end{array}$ \\
\hline
\end{tabular}

Fonte: Dados da pesquisa (2013)

De modo geral pode-se inferir que a cooperação acima descrita constituiu uma estratégia para as organizações pesquisadas unir forças, desenvolver atividades em conjunto, integrar conhecimentos, informações e experiências, o que possibilitou às pequenas e médias empresas a penetração no mercado internacional e a obtenção de sucesso no processo de internacionalização.

Destaca-se ainda que as contribuições ora apresentadas enquadram-se nos argumentos de Arruda e Arruda (1997) de que a formação de relacionamen- tos cooperativos pressupõe a existência da intenção de alcançar benefícios por parte dos parceiros envolvidos na relação, ainda que a intenção de cada um possa ser diferente, admitindo-se que enquanto um parceiro pode objetivar a internacionalização (empresa A, B, C), o outro pode fornecer tecnologia ou apoiar o processo de inserção internacional da empresa (fornecedores, despachantes, clientes, e outros) em uma relação de benefícios mútuos. 


\subsection{Tipos de Cooperação para a internacionali- zação}

As contribuições dos atores acima citados possibilitam a formação de diversos tipos de cooperação, conforme descrito no quadro 5 abaixo, o qual fundamenta-se nas disposições constantes no quadro 1 do referencial teórico.

Quadro 5 - Tipos de cooperação

\begin{tabular}{|c|c|c|}
\hline TIPO & ATOR & DESCRIĈ̃̃O \\
\hline $\begin{array}{l}\text { Cooperação } \\
\text { financeira }\end{array}$ & Bancos & $\begin{array}{l}\text { Possibilitou acessar a recursos financeiros para investir na adaptação do } \\
\text { parque fabril aos padrões internacionais de produção (Empresa A). }\end{array}$ \\
\hline \multirow{2}{*}{$\begin{array}{l}\text { Cooperação na } \\
\text { cadeia de su- } \\
\text { primentos da } \\
\text { logística inter- } \\
\text { nacional }\end{array}$} & $\begin{array}{l}\text { Despachante } \\
\text { aduaneiro }\end{array}$ & Despacho da carga para exportação (Empresas “A”, "B” e “C"). \\
\hline & $\begin{array}{l}\text { Empresa de } \\
\text { logística inter- } \\
\text { nacional } \\
\end{array}$ & $\begin{array}{l}\text { Operações logísticas de consolidação de carga e rateio de frete, impac- } \\
\text { tando na redução de custos (Empresas "A", "B" e "C"). }\end{array}$ \\
\hline $\begin{array}{c}\text { Cooperação } \\
\text { para a produção }\end{array}$ & Fornecedores & $\begin{array}{l}\text { Possibilitou acessar a insumos para o processamento do suco, viabili- } \\
\text { zando as operações de exportação (Empresas "A", "B" e "C" } \mathrm{C} \text { "). }\end{array}$ \\
\hline \multirow{2}{*}{$\begin{array}{l}\text { Cooperação } \\
\text { comercial }\end{array}$} & $\begin{array}{l}\text { Câmaras Frigo- } \\
\text { ríficas no Exte- } \\
\text { rior }\end{array}$ & $\begin{array}{l}\text { Possibilitou atender aos pedidos de forma mais rápida viabilizando fe- } \\
\text { char contratos com grandes clientes, de forma a ampliar a capacidade } \\
\text { operacional (Empresas "A" e "C"). }\end{array}$ \\
\hline & $\begin{array}{l}\text { Parceiro co- } \\
\text { mercial no } \\
\text { exterior }\end{array}$ & Possibilitou ingressar no mercado externo (Empresas “B”). \\
\hline $\begin{array}{l}\text { Cooperação em } \\
\text { marketing }\end{array}$ & Clientes & $\begin{array}{l}\text { Forneceu informações sobre o mercado externo, como forma de reforçar } \\
\text { o posicionamento mercadológico (Empresa "A"). }\end{array}$ \\
\hline
\end{tabular}

Fonte: Dados da pesquisa (2013).

Saturada a análise e discussão dos resultados, a seguir apresentam-se as conclusões do estudo.

\section{Conclusão}

A presente pesquisa apresentou o objetivo geral de analisar como a cooperação viabiliza o processo de internacionalização de pequenas e médias empresas do setor de bebidas do Estado de Sergipe.

O estudo de casos múltiplos, envolvendo três indústrias de pequeno e médio porte do segmento em destaque, revelou que as empresas cooperam com diversos atores, tanto localizadas no mercado doméstico (bancos, fornecedores, despachantes aduaneiros, empresas de logística) quanto no mercado internacional (locadores de câmara frigoríficos, clientes, parceiro comercial).

A pesquisa mostrou que a cooperação inteorganizacional desenvolvidas por estas empresas possibilitou a obtenção de diversos benefícios, tais como: redução de custos logísticos e de operações, acesso a novos mercados e obtenção de recursos produtivos e financeiros.
Em seguida, constatou-se que por meio destas vantagens foi possível alcançar os recursos necessários para ingressar e atuar no mercado internacional, os quais em caso de atuação isolada não seriam obtidos.

Neste sentido, o presente estudo apresenta como contribuições acadêmicas a confirmação dos pressupostos teóricos de que por meio da cooperação é possível neutralizar os fatores que impedem a atuação das pequenas e médias empresas no mercado internacional.

\section{Referências}

AMAL, M; FREITAG FILHO, A.; MIRANDA, C. M. S. Algumas evidências sobre o papel das redes de relacionamento e empreendedorismo na internacionalização das pequenas e médias empresas. Revista Faces de Administração Journal, v. 7, n. 1, p. 63-80, Belo Horizonte, janeiro/março, 2008.

AMATO NETO, J. Redes de cooperação produtiva e clusters regionais: oportunidades para as 
pequenas e médias empresas. São Paulo: Atlas, 2000.

ARRUDA, M. C. C.; ARRUDA, M. L. Alianças estratégicas internacionais: formação e estruturação em indústrias manufatureiras. RAE - Revista de Administração de Empresas, São Paulo, v. 37, n. 4, p. 28-37, out./dez. 1997

BALESTRIN, A.; VARGAS, L. M. Evidências teóricas para a compreensão das redes interorganizacionais. In: ENCONTRO NACIONAL DE ESTUDOS

ORGANIZACIONAIS, 2., 2002, Recife, Anais... Recife: ANPAD, 2002.

BALESTRIN, A.; VARGAS, L. M. A dimensão estratégica das redes horizontais de PMEs: teorizações e evidências. RAC - Revista de Administração Contemporânea, Curitiba, v. 8, Ed. Espec., p. 203-228, 2004

BALESTRIN, A., VARGAS, L. M., FAYARD, P. Criação de conhecimento nas redes de cooperação interorganizacional. Revista de Administração de Empresas, v. 45 n.3, p.52-64, 2005.

BALESTRIN, A.; VERSCHOORE, J. Redes de cooperação empresarial: estratégias de gestão na nova economia. Porto Alegre: Artmed Editora AS, 2008.

BALESTRIN, A.; VERSCHOORE, J. R.; REYESJUNIOR, E. O Campo de estudos sobre redes de cooperação interorganizacional no Brasil. RAC Revista de Administração Contemporânea, Curitiba, v. 14, n.4, p.458-477, maio/junho, 2010.

BARDIN, L. Análise de conteúdo. Lisboa: Edições 70, 2008.

BOEHE, D. M., TONI, D. T. Modelo para internacionalização de empresas baseada em redes. In: SIMPÓSIO DE GESTÃO DA INOVAÇÃO TECNOLÓGICA. 24., 2006, Gramado, Anais... Gramado: ANPAD, 2006.
BRITO, C. M. Estratégias de Internacionalização e cooperação. Working paper $n^{\circ} 38$, Faculdade de Economia do Porto, 1993.

CALDAS, P. T.; VASCONCELOS, A. C. F.; ANDRADE, E. O.; CÂNDIDO, G. A.

Estratégias para internacionalização de empresas com atuação em redes: um estudo exploratório em um consórcio de exportação no setor de confecções. Revista GEPROS - Gestão da Produção, Operações e Sistemas, Bauru, v. 5, n. 3, p. 93-111, julho/setembro, 2010

CÂNDIDO, G. A. A formação de redes interorganizacionais como mecanismo para geração de vantagem competitiva e para promoção do desenvolvimento regional: o papel do estado e das políticas públicas neste cenário. REAd - Revista Eletrônica de Administração, Porto Alegre, vol. 8 n. 4, julho/agosto. 2002.

Fatores críticos de sucesso no

processo de formação, desenvolvimento e viabilização de redes organizacionais: um estudo exploratório. In: ENCONTRO DA

ASSOCIAÇÃO NACIONAL DE PÓSGRADUAÇÃO E PESQUISA EM ADMINISTRAÇÃO, 28., 2004, Curitiba. Anais... Curitiba: ANPAD, 2004

CARON, A. F. NASCIMENTO, D. E. As dificuldades para o empreendedor internacionalizar sua pequena empresa: influência do "custo brasil". Cadernos da Escola de Negócios. v. 1, n. 10, p. 60-73, 2012

CHETTY, S.; AGNDAL, H. Social capital and its influence on changes in internationalization mode among small and medium-sized enterprises. Journal of International Marketing, Chicago, v. 15, n. 1, p. 1-29, 2007.

CHETTY, S.; CAMPBELL-HUNT, C. A strategic approach to internalization: a traditional versus a "born global" approach. Journal of International Marketing, Chicago, v. 12, n. 1, p. 57-81, 2004.

CHETTY, S. K.; WILSON, H. I. M. Collaborating with competitors to acquire resources. International Business Review, v. 12, p. $61-81,2003$ 
COSTA, P. R.; FERREIRA, M. A. T. A interação e a cooperação como fontes de competitividade e aprendizagem na pequena e média indústria brasileira. Revista Perspectiva em Ciência da Informação, Belo Horizonte, v. 5, n. 2, p. 183 203, julho/dezembro, 2000.

COVIELLO, N. E. The network dynamics of international new ventures. Journal of International Business Studies, Hampshire, UK, v. 37, n.5, 2006.

COVIELLO, N. E.; MCAULEY, A. Internationalisation and the smaller firm: a review of contemporary empirical research. Management International Review, Wiesbaden, Germany, v. 39, n.3, p. 223-57, 1999

CRESWELL, J. Research design: qualitative e quantitative, and mixed approaches. $2^{\text {nd }} \mathrm{ed}$. Thousand Oaks: Sage, 2002.

EIRIZ, V. Proposta de tipologia sobre aliança estratégica. RAC - Revista de Administração Contemporânea, Curitiba, v. 5, n. 2, p. $65-90$, maio/agosto, 2001.

FENSTERSEIFER, J. E. Internacionalização e cooperação: dois Imperativos para a empresa do terceiro milênio. REAd - Revista Eletrônica de Administração, Porto Alegre, v. 6, n. 3, p. 1 - 9, outubro, 2000.

FENSTERSEIFER, J. E; VIEIRA, L. M. As opções estratégicas das empresas locais em face da globalização da atividade produtiva: um estudo exploratório na cadeia do leite. Revista de Administração UFLA, Lavras, v. 4, n. 2, p. 3-15, janeiro/dezembro, 2002

FRANCO, M.J.B. Tipologia de processos de cooperação empresarial: uma investigação empírica sobre o caso português. RAC - Revista de Administração Contemporânea, Curitiba, v. 11, n. 3, p. 149-176, julho/setembro, 2007.

FREEMAN, S.; EDWARDS, R.; SCHRODER, B. How smaller born global firms use networks and alliances to overcome constraints to rapid internationalization. Journal of International Marketing, v. 14, n. 3, p. 33-63, Chicago, 2006
GALLON, A.V; ENSLIN, S.R; SILVEIRA, A. Rede de relacionamentos em pequenas empresas de base tecnológica (ebts) incubadas: um estudo da sua importância para o desempenho organizacional na percepção dos empreendedores. Revista de Gestão da Tecnologia e Sistemas de Informação, São Paulo, v. 6, n. 3, p. 551-572, janeiro/dezembro, 2009.

GODOY, A. S. Pesquisa qualitativa: tipos fundamentais. RAE - Revista de Administração de Empresas, São Paulo, v. 35, n.3, p. 20-29, maio/Junho, 1995.

HALL, R. Organiza-

tions. structures, processes and outcomes. $5 \mathrm{ed}$. Englewood Cliffs: Prentice Hall, 1991. Unit XII: Interorganizational relationships, p. $216-243$.

HALL, R. Organiza-

tions. structures, processes and outcomes. $5 \mathrm{ed}$. Englewood Cliffs: Prentice Hall, 1991. Unit XII: Interorganizational relationships, p. $216-243$.

HOLLENSTEIN, H. Determinants of international activities: are SMEs different? Small Business Economics, v. 24, n. 5, p. 431-450, june, 2005

JARRILLO, J.C. On strategic networks. Strategic Management Journal, v. 9, p. 31-41, 1998.

JOHANSON, J.; VAHLNE, J.E. The mechanism of Internationalization. International Marketing Review, v. 7, n. 4, p.11-24, 1990

JOHNSEN, R. E.; JOHNSEN, T. E. International market development through networks. the case of the Ayrshire knitwear sector. International Journal of Entrepreneurial Behavior \& Research. v. 5 , n. 6 , p. 297-312, 1999

JUCHNIEVSKI, L. C.; SOARES, I. T. Consórcio de exportação como alternativa de internacionalização para pequenas empresas. Revista de Administração, v. 11, n. 20, p. 70-84, 2013

LEVY, P. B.; MOTA, M. C.; WERMELINGER, M. B. O uso de networks no processo de internacionalização: aplicação a pequenas e médias empresas. Internext - Revista Eletrônica de Negócios Internacionais da ESPM, São Paulo, v. 5, n. 1, p. 50-83, jan./jun. 2010

RGC, Santa Maria, v.2, n.4, Págs. 01-16, jul./dez. 2015 
MAGALHÃES, J. M.; DAUDT, C. G.; PHONLOR, P. R. Vantagens proporcionadas às pequenas $\mathrm{e}$ médias empresas por meio da união em redes de cooperação no contexto do venture capital. RAC - Revista de Administração Contemporânea, Curitiba, v. 13 , n. 4 , art. 4, pp. 583-603, outubro/dezembro, 2009.

MAZZATO, A. R; GOLO, S. S. Redes de cooperação como vantagem competitiva: estudo de caso de uma rede de supermercados no Rio Grande do Sul. Revista REDES, Santa Cruz do Sul, v. 16, n. 2, p. 227 - 252, maio/agosto, 2011.

MARTINS, G. A. Estudo de Caso: uma estratégia de pesquisa. 2. ed. São Paulo: Atlas, 2008

\section{MDIC - MINISTÉRIO DO DESENVOLVIMEN-} TO, INDÚSTRIA E COMÉRCIO EXTERIOR . Comércio Exterior. Estatística comercial Brasileira. 2013. Disponível em:

<http://www.desenvolvimento.gov.br/sitio/intern a/index.php?area $=5>$. Acesso em 30 de junho de 2013.

\section{MDIC - MINISTÉRIO DO DESENVOLVIMEN-} TO, INDÚSTRIA E COMÉRCIO EXTERIOR. Balança Comercial Brasileira. Dados Consolidados. 2014. Disponível em http://www.desenvolvimento.gov.br//arquivos/d wnl_1423144482.pdf. Acesso em 29 de junho de 2014.

NEUMAN, Lawrence W. Social research methods: qualitative and quantitative approaches. 3. ed. Boston: Allyn \& Bacon, Cap 2 -Dimension of Research. p 18 a 35, 1997

OLIVEIRA, M. F; MARTINELLI, D. P. A internacionalização de pequenas empresas através de consórcios de exportação inseridos em clusters industriais: uma relação recíproca de contribuição. Revista Internacional de Desenvolvimento Local, Campo Grande, v. 6, n.10, p.55-63, março, 2005.

OLIVEIRA, S. R . G. BRUNI, A. L. Consórcios de exportação de pequenas e médias empresas de moda praia localizadas em arranjos produtivos locais - caminho para internacionalização? In: ENCONTRO DE ESTUDOS EM ESTRATÉGIA, 4., 2009, Recife. Anais... Recife: ANPAD, 2009

PACAGNAN, M. N. Alianças estratégicas e redes colaborativas como alternativa competitiva para o pequeno varejista: um estudo de comparativo. Revista de Gestão USP, São Paulo, v. 13, Número especial, p. 19-30, 2006.

POZZO, D. N; FINGER, A.B; Alianças estratégicas em operações internacionais: o estudo de caso de um international freight forwarder. IN: SIMPÓSIO DE ADMINISTRAÇÃO DA PRODUÇÃO, LOGÍSTICA E OPERAÇÕES INTERNACIONAIS, 8., 2010, São Paulo. Anais... São Paulo: FGV-EAESP, 2010.

POWELL, W. W. Learning from collaboration: knowledge and networks in the biotechnology and pharmaceutical industries. California Management Review, v.40, n.3, p. 228-240, 1998.

PRASHANTHAM, S. Foreign network relationships and the internationalization of small knowledge-intensive firms. International Journal of Entrepreneurship \& Innovation Management, Buckinghamshire, UK, v. 6, n. 6, p. 4, 2006.

REIS, J.A,; EL-KOUBA, A.;QUANDT, C.O.; CRUZ, J.A.W.; MARTINS, T.S. Cooperação e desenvolvimento: estudo de caso em uma rede de cooperação. Revista Gerenciais, São Paulo, v.7, n.1, p.21-28, junho, 2008

RICHARDSON, R. J. Pesquisa social: métodos e técnicas. 3. ed. São Paulo: Atlas, 1999.

SANTOS, L. B. Políticas públicas e internacionalização de empresas brasileiras. Revista Soc. \& Nat. v. 27, n. 1, p. 37-52, jan/abr/, 2015.

SAUNDERS, M; LEWIS, P.; THORNILL, A. Research Methods for Business Students. 2.ed. Harlow, England: Pearson Education, 2000. Cap 4- Pg 84 a 95 
SCHERMERHORN, J.R. Determinants of interorganizational cooperation. Academy of Management Journal, New York, v. 18, n. 4, p. 846-856, December, 1975.

SEBRAE, Serviço Brasileiro de Apoio às Micro e Pequenas Empresas. Sondagem junto às MPE exportadoras atendidas pelo SEBRAE. Brasília: SEBRAE, 2007.

SEBRAE - SERVIÇO BRASILEIRO DE APOIO ÀS MICRO E PEQUENAS EMPRESAS Anuário do trabalho na micro e pequena empresa. 3a ed. Brasília/ DF: SEBRAE, 20113a

Sobrevivência das Empresas no Brasil. Brasília/ DF: SEBRAE, 2013 b.

Taxa de sobrevivência das empresas no Brasil. Brasília/DF: SEBRAE, 2011.

\section{SECRETARIA DE ESTADO DO}

\section{DESENVOLVIMENTO ECONÔMICO E DA} CIÊNCIA E TECNOLOGIA DE SERGIPE -

SEDETEC. Balança comercial de Sergipe, 2012. Disponível em: <http: www.sedetec.se.gov.br $>$ Acesso em 20 de novembro de 2012.

SOUZA, M. C. A. F.; BACIC, M. J. Pensando políticas para as pequenas empresas: importância das formas de inserção e as condições de apropriação dos benefícios. REE, Brasília, p. 3-16, jun. 1998

VERSCHOORE, J. R.; BALESTRIN, A. Fatores competitivos das empresas em redes de cooperação. In: ENCONTRO NACIONAL DOS PROGRAMAS DE PÓS-GRADUAÇÃO EM ADMINISTRAÇÃO, 30., 2006, Salvador, Anais... Salvador: ANPAD, 2006.

VERSCHOORE, J. R.; BALESTRIN, A. Fatores relevantes para o estabelecimento de redes de cooperação entre empresas do Rio Grande do Sul. RAC - Revista de Administração Contemporânea, Curitiba, v. 12, p. 1043-1069, outubro/dezembro, 2008

VINHAS, A. P. L. C.; BECKER, G. V. Redes de cooperação interorganizacional: $\mathrm{O}$ caso da rede macsul. Revista Análise, Porto Alegre, v. 17, n. 1, p. 167-184, janeiro/julho, 2006.
WAARDEN, F. V. Emergence and development of business interest associations: an example from the Netherlands. Organization Studies, v.13, n.4, p. 521-562, 1992

WINCKLER, N.C.; MOLINARI, G.T. Competição, colaboração, cooperação e coopetição: revendo os conceitos em estratégias interorganizacionais. Revista ADMpg Gestão Estratégica. Ponta Grossa, v. 4, n. 1, p. 145-150, janeiro/dezembro, 2011 .

YIN, R. Estudo de caso: planejamento e métodos. 3. ed. Porto Alegre: Bookman, 2005.

ZAHRA, S. A., UCBASARAN, D., NEWEY, L. R. Social knowledge and SMEs' innovative gains from internationalization. European Management Review, v. 6, n. 2, p. 81-93, summer, 2009. 
